\title{
Barrier Properties of Coated and Laminated Polyolefin Films for Food Packaging
}

\author{
V.L. Lazićc ${ }^{a}$, J. Budinski-Simendićc ${ }^{a *}$, J.J. Gvozdenović ${ }^{b}$ And B. Simendić ${ }^{b}$ \\ ${ }^{a}$ University of Novi Sad, Faculty of Technology, Bulevar Cara Lazara 1, Novi Sad, Serbia \\ ${ }^{b}$ The Higher Educational Technical School of Professional Studies, Novi Sad, Serbia
}

\begin{abstract}
The food packaging industry demands polymer films possessing a defined barrier against permeation of gases, moisture and flavor. The objective of this study was to assess the differences between the barrier properties of coated and un-coated polyolefine films. Eight types of packaging films are prepared by standard industrial procedure by cast film extrusion processing with chill rollers: biaxially oriented polypropylene (BOPP), BOPP coated by acrylic copolymer, metallized BOPP by aluminum, and low-density polyethylene (LDPE). The influence of lamination and metallization on the gas molecules $\left(\mathrm{CO}_{2}, \mathrm{O}_{2}\right.$ and $\left.\mathrm{N}_{2}\right)$ was determined by Lyssy's method. The moisture transparency was assessed according to the gravimetric method. The substantial differences between the barrier properties of the coated and un-coated films were estimated. It was estimated that the lamination process improves the oxygen barrier but not necessarily the moisture barrier, due to the different mechanisms for oxygen and moisture permeability. The obtained barrier properties data were considered from a practical point of view. It was concluded that films based on metallized BOPP has excellent barrier properties and can be used to over wrap food products.
\end{abstract}

PACS numbers: 82.35.Lr, 66.30.Pa, 82.80.Bg, 68.60.-p

\section{Introduction}

The purpose of food packaging is to preserve the quality of the food from its manufacture to consumer use. The most common quality losses are associated with water vapor and oxygen transfer [1]. The research of barrier properties is very important from a technological point of view [2-3]. Thus the diverse part of the material science field has many applications to food package on laboratory or industrial scale [4-6]. The manufacturing demands for polymer packaging films with defined barrier against gases, moisture and flavors are now very restrictive [7-12]. It is also of big interest to study the effect of irradiation on plastics packaging materials properties [13]. The gas transport coefficients vary generally with parameters which can be intrinsic to the polymer, such as the degree of crystallinity, the nature of the polymer, or even the thermal and mechanical histories of samples. Molecular orientation which usually develops in processing is known to have a major effect on the mechanical properties of both glassy and crystalline polymers. In order to achieve good barrier laminates, one key issue along the whole production chain (from film extrusion to lamination) is given by the material surface properties. Orientation of macromolecular chains reduces gas diffusivity. The high-barrier packaging can comprise several

* corresponding author; e-mail: jarkamer@gmail.com different layers and various types of resins, which provide advanced properties for such things as extended shelf life and the ability to let in certain gases to change product coloring. The interaction of water with a polymer depends on the polarity of its functional groups and influences the mechanism of diffusion transport in macromolecular compounds. It is well known that strength and stiffness of films increase as density goes up, while permeability goes down [14]. In recent years, especially biaxially oriented polypropylene films (BOPP) has become one of the most popular high growth films in the world market. The oxygen transmission of biaxially oriented PP was shown to be modifiable by vapor deposition of melamine, which formed a transparent uniform layer on polymeric films. The vapor-deposited melamine molecules underwent a large number of cooperative hydrogen bond interactions leading to a coherent layer of an infinite supramolecular network. The vacuum coating process is expected to be of use in the field of transparent polymeric barrier films for applications such as food packaging. According to Jahromi [15] to obtain a controlled atmosphere favorable for food conservation, packages must have good barrier properties. Some tend to adjust the film permeability to the respiratory intensity by means of micro-perforations, as for instance obtained with bi-oriented polypropylene films. For some applications the industrial recuperation material can also be included Nevertheless, in most cases, a better selectivity is obtained to the detriment of the permeability. A third 
method consists from a judicious choice of molecules to form a monolayer film, which will give the ad hoc permeability and selectivity. The reduction of the oxygen permeability of different BOPP films by vacuum web coating and laminating depends on the surface structure and not on the thickness of the BOPP films. Vacuum metallized materials are made by the deposition of metal, typically aluminum, in specially designed and constructed equipment under high vacuum.

\section{Materials and method}

\subsection{Materials}

In the present work the following materials were used: Polypropylene granulated (PP) MI $=1.3-1.8 \mathrm{~g} / 10 \mathrm{~min}$, (Hipol, Odžaci, Serbia); Metallized oriented polypropylene, laminated roll stock of vacuum deposited aluminium BOPP films thickness $400 \AA$; Acrylic coating - copolymer of alkylacrylates and acrylic acid (Acronal, BASF); Polyvinylidene chloride (Dow Chemical); Polyethylene (PE) granulated, Density 0.917, MI $=1.8 \mathrm{~g} / 10 \mathrm{~min}$, (HIP, Pancevo, Serbia).

\subsection{Sample preparation}

Eight types of coated and un-coated food packaging films are prepared by standard industrial procedure (Viskoza - Lofolen, Loznica, Serbia) by cast film extrusion processing with chill rollers (Some technology parameters were: chill roll temperature $20-60^{\circ} \mathrm{C}$, melt temperature $220-280^{\circ} \mathrm{C}$, speed $150-450 \mathrm{~m} / \mathrm{min}$, gauge range 20-90 $\mu \mathrm{m})$. Structure and thickness of coated and uncoated films are designated in the Table I.

TABLE I

Structure and notation for eight types of food packaging films.

\begin{tabular}{c|l}
\hline \hline Sample & \multicolumn{1}{|c}{$\begin{array}{c}\text { Structure and thickness } \\
\text { of coated and un-coated films }\end{array}$} \\
\hline 1 & BOPP $(40 \mu \mathrm{m})$ \\
2 & acrylic/BOPP $(25 \mu \mathrm{m}) /$ acrylic \\
3 & BOPP $(20 \mu \mathrm{m}) / \mathrm{BOPP}(20 \mu \mathrm{m})$ \\
4 & $\mathrm{BOPP}(20 \mu \mathrm{m}) / \mathrm{Al} / \mathrm{BOPP}(20 \mu \mathrm{m})$ \\
5 & $\mathrm{PVDC} / \mathrm{BOPP}(20 \mu \mathrm{m}) / \mathrm{PE}(20 \mu \mathrm{m})$ \\
6 & $\mathrm{PE}(20 \mu \mathrm{m})$ \\
7 & $\mathrm{PE}(50 \mu \mathrm{m})$ \\
8 & $\mathrm{PE}(90 \mu \mathrm{m})$
\end{tabular}

\subsection{Analytical methods}

The gas permeability determinations of $\mathrm{CO}_{2}, \mathrm{~N}_{2}$ and $\mathrm{O}_{2}$ have been done by using the Lyssy instrument GPM-200 with belonging gas chromatograph Gasukuro Kogyo GC-320 and integrator HP 3396 A. This process involved simultaneous determination of gas concentration on both sides of the film or foil samples. The investigations have been performed at $23^{\circ} \mathrm{C}$ and 1 bar pressure difference, on five parallel samples, till the constant permeability values. The samples were prepared by placing a film specimen in the center of an adhesive aluminum foil with a hole through which the oxygen permeability was tested. Mixture of gases $\left(\mathrm{CO}_{2}, \mathrm{~N}_{2}, \mathrm{O}_{2}\right)$ in desired rations circulated over one side of the foil, while the helium circulates on the other side. The pressure on both sides was the same (0.2 bar). Gradually, helium is enriched due to the diffusion of gases from the gaseous mixture through the foil. The diffusion depends on foil permeability, and is recorded by the gas chromatograph and integrator during $24 \mathrm{~h}$ at desired intervals according the expected values of film permeability. The permeability of air has been calculated on the bases of instrument calibration data. The results of permeability determination were expressed according to applied Lissy method (in $\mathrm{ml} / \mathrm{m}^{2} /$ day at pressure difference of $1 \mathrm{bar}$ ). The test gas mixture in the required concentrations was obtained from (Gas, Pancevo, Serbia) with certified data for gas proportions $(33.3 \% ; 33.3 \% ; 33.3 \%)$. Before mixing the gases (oxygen, carbon IV oxide and nitrogen) were quoted as $99.5 \%$ - $99.8 \%$ pure. Water Vapor Permeation through the films was determined using aluminum test dishes according to the ASTM E-96-67 method.

\section{Results and discussion}

Since barrier properties of packaging material are responsible for product quality deterioration, the detailed understanding of the characteristics of coated films is great practical and commercial importance. Therefore, design and optimization of the coating composition become more important for food packaging materials. This paper focuses on the lamination, coating and film thickness. The experimental data were considered from a practical point of view. The values for the air permeability for all films are calculated using the data for perme-

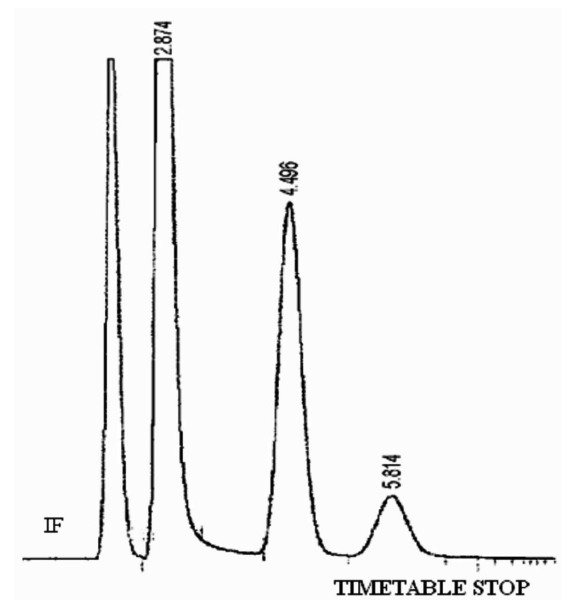

Fig. 1. Final gas permeability chromatogram obtained according to standardized procedure for polypropylene film BOPP $(40 \mu \mathrm{m})$. 


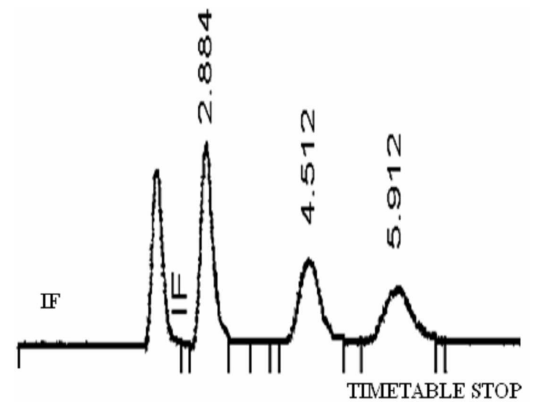

Fig. 2. Final gas permeability chromatogram obtained according to standardized procedure for polypropylene film coated by acrylic copolymer acrylic/BOPP $(25 \mu \mathrm{m}) /$ acrylic.

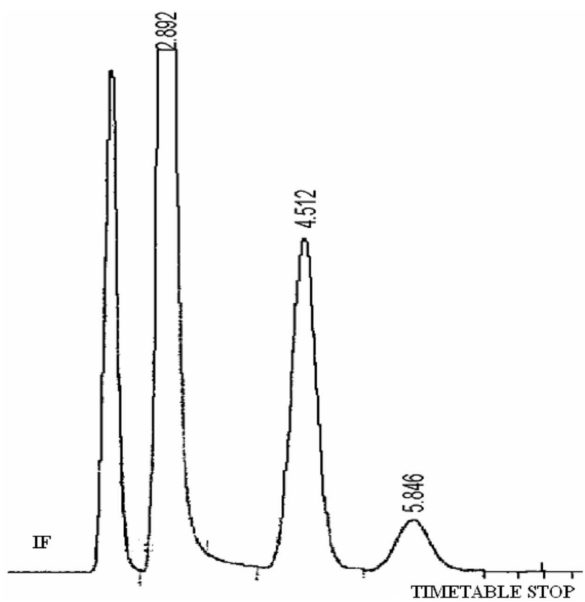

Fig. 3. Final gas permeability chromatogram obtained according to standardizedprocedure for laminated polypropylene packaging film BOPP $(20 \mu \mathrm{m}) /$ BOPP $(20 \mu \mathrm{m})$.

ability of oxygen, carbon IV oxide and nitrogen. The barrier properties of experimentally considered laminated, coated and uncoated polyolefin films are summarized in the Table II. The final chromatograms for gas permeability determinations for some type of food packaging films are shown in the Figs. 1-3. The peaks area of the obtained chromatograms increased during the measurements and the final values obtained via standardized procedure represent the permeability of gases from the initial mixture over the foil. The good oxygen-barrier properties of coated PP films are critical for achieving a long shelf-life for the packaged food products as water barrier properties.

From data given in Table II, a substantial differences between the barrier properties of the investigated coated and uncoated polyolefine films were estimated. The obtained results demonstrate that the film lamination process can strongly influence the film gas permeability. The lamination process always improves the oxygen barrier but not necessarily the moisture barrier, as there are different mechanisms for oxygen and moisture permeability. The influence of thickness on the final functionality of the laminate also depends on the parameters of the used polyethylene. Concluding, there are different mechanisms for the permeability of gas and moisture through vacuum-coated films and laminates. Oxygen and moisture barriers of web-coated films depend strongly on the structure of the interface between the polymer and the layer, as well as on the properties of the coated layer. Environmentally thinking, aluminum metallizing meets the environmental and source reduction requirements; in fact, since the aluminum coatings are a molecular layer, metallized substrates are considered mono-materials. Besides providing an effective barrier to atmospheric gases and aroma constituents, metallizing also prevents light from entering. Light is undesirable since it may also be a catalyst for the oxidation of the fat. Polyolefins like high-density polyethylene are outstanding barriers to moisture but are highly permeable to hydrocarbons. The interaction of water with a polymer depends on the polarity of its functional groups and influences the mechanism of diffusion transport in macromolecular compounds.

TABLE II

Permeability of gasses $\left(\mathrm{ml} / \mathrm{m}^{2} /\right.$ day, p1bar) for different packaging films.

\begin{tabular}{c|l|c|c|c|c}
\hline \hline $\mathrm{N}$ & \multicolumn{1}{|c|}{ Sample } & $\mathrm{CO}_{2}$ & $\mathrm{O}_{2}$ & $\mathrm{~N}_{2}$ & Air \\
\hline 1 & BOPP $(40 \mu \mathrm{m})$ & 2997.9 & 1130.8 & 257.5 & 442.8 \\
2 & acrylic/BOPP $(25 \mu \mathrm{m}) /$ acrylic & 197.9 & 70.6 & 11.5 & 31.6 \\
3 & $\mathrm{BOPP}(20 \mu \mathrm{m}) / \mathrm{BOPP}(20 \mu \mathrm{m})$ & 2825.4 & 929.8 & 184.9 & 343.1 \\
4 & $\mathrm{BOPP}(20 \mu \mathrm{m}) / \mathrm{Al} / \mathrm{BOPP}(20 \mu \mathrm{m})$ & 183.9 & 44.6 & 28.3 & 31.8 \\
5 & $\mathrm{PVDC} / \mathrm{BOPP}(20 \mu \mathrm{m}) / \mathrm{PE}(20 \mu \mathrm{m})$ & 87.0 & 25.3 & 11.7 & 14.06 \\
6 & $\mathrm{PE}(20 \mu \mathrm{m})$ & 26098.0 & 4849.3 & 3488.4 & 3775.6 \\
7 & $\mathrm{PE}(50 \mu \mathrm{m})$ & 17612.0 & 3058.2 & 831.0 & 1306.6 \\
8 & $\mathrm{PE}(90 \mu \mathrm{m})$ & 7350.4 & 2439.2 & 573.0 & 949.4
\end{tabular}


Low-density polyethylene is known for its flexibility, moisture protection, toughness, chemical resistance, lightweight, sealing properties, and low cost However, it cannot be used alone because of its poor gas resistance, inability to retain ink, and its strong tendency to develop a static charge that may attract dust, which can be unsightly on a retail shelf In order to assess the influence of film thickness on the gas transport of polyethylene films (range 20-90 $\mu \mathrm{m}$ ) are considered for receiving some predictive rules for practical purposes. According obtained data it was estimated that films based on metallized BOPP have good mechanical and barrier properties and can be used for specific applications. The results for the water vapor permeability are summarized in the Table III, and comparative diagram for eight types of barrier films are given in the Fig. 4 . The barrier to water vapor increased by 2 times after coating. It can be observed that all samples have good barrier properties respecting to the food packaging standards.

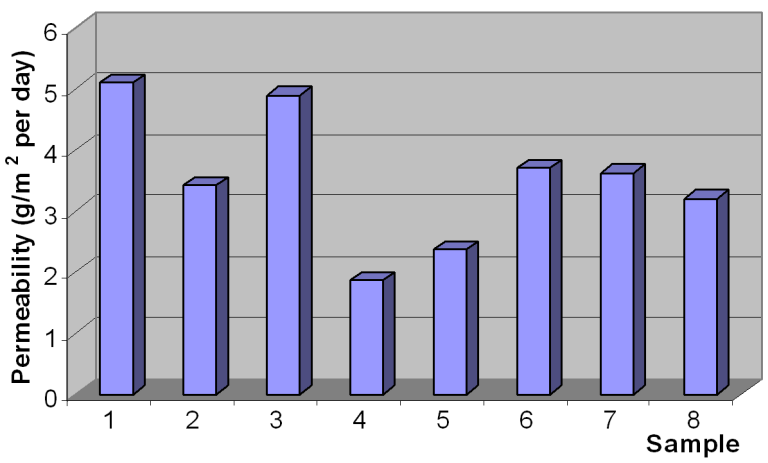

Fig. 4. Comparative values of water vapor permeability for 8 different types of packaging films: 1 BOPP $(40 \mu \mathrm{m}) ; 2$ acrylic/BOPP $(25 \mu \mathrm{m}) /$ acrylic; 3 BOPP $(20 \mu \mathrm{m}) / \mathrm{BOPP}(20 \mu \mathrm{m}) ; \underline{4} \mathrm{BOPP}(20 \mu \mathrm{m}) / \overline{\mathrm{Al}} / \mathrm{BOPP}$ $(20 \mu \mathrm{m}) ; \underline{5} \mathrm{PVDC} / \mathrm{BOPP}(20 \mu \mathrm{m}) / \mathrm{PE}(20 \mu \mathrm{m}) ; \underline{6} \mathrm{PE}$ $(20 \mu \mathrm{m}) ; \underline{7} \mathrm{PE}(50 \mu \mathrm{m}) ; \underline{8} \mathrm{PE}(90 \mu \mathrm{m})$.

TABLE III

Water vapor permeability $\left(\mathrm{g} / \mathrm{m}^{2}\right.$ per day)

\begin{tabular}{c|l|c}
\hline \hline Sample & \multicolumn{1}{|c|}{ Structure of packaging film } & $\begin{array}{c}\text { Water vapor } \\
\text { permeability }\end{array}$ \\
\hline 1 & BOPP $(40 \mu \mathrm{m})$ & 5.09 \\
2 & Acrylic/BOPP $(25 \mu \mathrm{m}) /$ acrylic & 3.42 \\
3 & BOPP $(20 \mu \mathrm{m}) / \mathrm{BOPP}(20 \mu \mathrm{m})$ & 4.89 \\
4 & BOPP $(20 \mu \mathrm{m}) / \mathrm{Al} / \mathrm{BOPP}(20 \mu \mathrm{m})$ & 1.85 \\
5 & $\mathrm{PVDC} / \mathrm{BOPP}(20 \mu \mathrm{m}) / \mathrm{PE}(20 \mu \mathrm{m})$ & 2.37 \\
6 & $\mathrm{PE}(20 \mu \mathrm{m})$ & 3.70 \\
7 & $\mathrm{PE}(50 \mu \mathrm{m})$ & 3.62 \\
8 & $\mathrm{PE}(90 \mu \mathrm{m})$ & 3.20
\end{tabular}

\section{Conclusion}

From obtained results it was concluded that the lamination process strongly influenced the film gas permeability. It was assessed that all samples have good barrier properties respecting to the food packaging standards. The influence of thickness on the final functionality of the laminate also depends on the parameters of used polymers. It was determined that films based on metallized BOPP has excellent barrier properties and can be used to over wrap food products. All considered multi-layer high-barrier foils with minimal permeability of $\mathrm{CO}_{2}, \mathrm{O}_{2}$ and $\mathrm{N}_{2}$ molecules (produced under estimated optimal technology parameters) were convenient for the preservation of vegetables in a modified atmosphere or mayonnaise, snack products, noodles, cereals, and spices.

\section{References}

[1] F. Tihminlioglu, I. Atik, B. Ozen, Journal of Food Engineering, 96, 342 (2010).

[2] W. Jang, I. Rawson, J.C. Grunlan, Thin Solid Films 516, 4819 (2008).

[3] M. Minelli, M.G. De Angelis, F. Doghieri, M. Marini, M. Toselli, F. Pilati: European Polymer Journal 44, 2581 (2008)

[4] D. Pereira de Abreu, P. Paseiro Losada, I. Angulo, J.M. Cruz, European Polymer Journal 43, 2229 (2007).

[5] N.H. Ullsten, M.S. Hedenqvist, Polymer Testing 22, 291 (2003).

[6] S. Marais, J.M. Saiter, C. Devallencourt, Q. Nguyen, M. Metayer, Polymer Testing 21, 425 (2002).

[7] R.S. Jagadish, B. Raj, M.R. Asha, Journal of Applied Polymer Science 113, 3732 (2009).

[8] M.D. Steven, J.H. Hotchkiss, Packaging Technology and Science 15, 17 (2002).

[9] N. De Kruijf, M. Van Beest, R. Rijk, Food Additives \& Contaminants 19, 144 (2002).

[10] B. Pajin, V. Lazić, O. Jovanovic, J. Gvozdenovic, International Journal of Food Science \&5 Technology 41, 717 (2006).

[11] J.W. Rhim, S.I. Hong, C.S. Ha, LWT-Food Science and Technology, 42, 612 (2009).

[12] V. Triantafyllou, A. Karamani, K. Akrida-Demertzi, P. Demertzis, European Food Research Technology 215, 243 (2002).

[13] S. Chytiri, A.E. Goulas, A. Badeka, K. Riganakos, D. Petridis, M.G. Kontominas, Radiation Physics and Chemistry 77, 1039 (2008).

[14] R. Romanić, E. Dimić, V. Lazić, V. Vujasinović, Acta Alimentaria 38, 319 (2009).

[15] S. Jahromi, U. Moosheimer, Macromolecules 33, 7582 (2000). 